
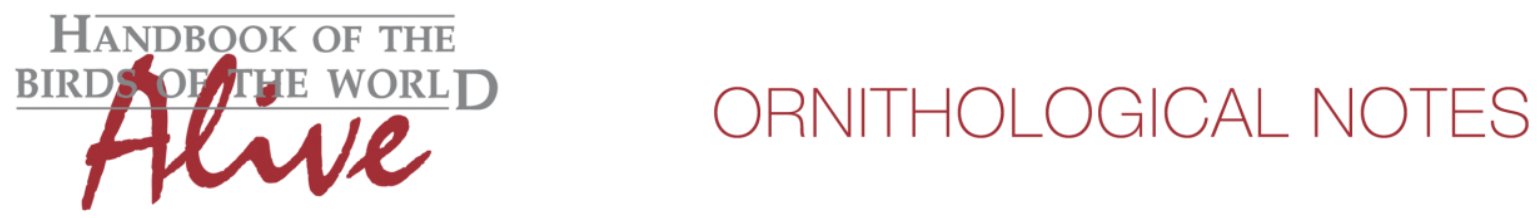

\title{
Notes on the vocalizations of Dusky Antbird (Cercomacra tyrannina).
}

Peter Boesman

In the following we briefly analyze and compare voice of the different races of Dusky Antbird (Cercomacra tyrannina). We also try to quantify the extent of any vocal differences using the criteria proposed by Tobias et al. (2010), as a support for taxonomic review.

We have made use of sound recordings available on-line from Xeno Canto (XC).

A quick check of the male loudsong indicates there is a clear difference between CentralAmerican birds (with the Magdalena valley, Colombia) and Guianan/Amazonian birds (east of the Andes). The first group has a high-pitched and rising song, the latter a somewhat lowerpitched and rising/falling song.

The situation of W Ecuadorian birds is less clear (they presumably belong to tyrannina, although have been called rufiventris in the past) for which it is better to analyze them as a separate group (Fig. 1).

In the following we have measured some basic parameters of male loudsong for those 3 groups:

Group 1: Central America and Magdalena valley

\begin{tabular}{ll}
\hline total length & $1.53-2.24 \mathrm{~s}$ \\
\# of notes & $12-17$ \\
max. freq. & $3000-3600 \mathrm{~Hz}$ \\
av. pace & $0.12-0.15$ \\
freq. range & $400-600 \mathrm{~Hz}$ \\
max. freq. last note & $2900-3450 \mathrm{~Hz}$
\end{tabular}

Group 2: West of Andes

$\begin{array}{ll}\text { total length } & 1.67-2.3 \mathrm{~s} \\ \text { \# of notes } & 15-29 \\ \text { max. freq. } & 2480-2600 \mathrm{~Hz} \\ \text { av. pace } & 0.075-0.11 \\ \text { freq. range } & 300-850 \mathrm{~Hz} \\ \text { max. freq. last note } & 1680-2200 \mathrm{~Hz}\end{array}$

Group 3: W Ecuador (no recordings from Colombian Chocó region)

total length

2.16-2.62s

\# of notes

14-19

max. freq.

$2990-3260 \mathrm{~Hz}$

av. pace

0.12-0.154

freq. range

$550-1300 \mathrm{~Hz}$

max. freq. last note

$1800-2750 \mathrm{~Hz}$ 


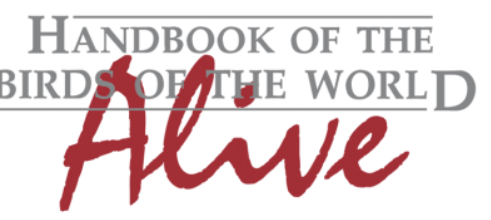

\section{ORNITHOLOGICAL NOTES}
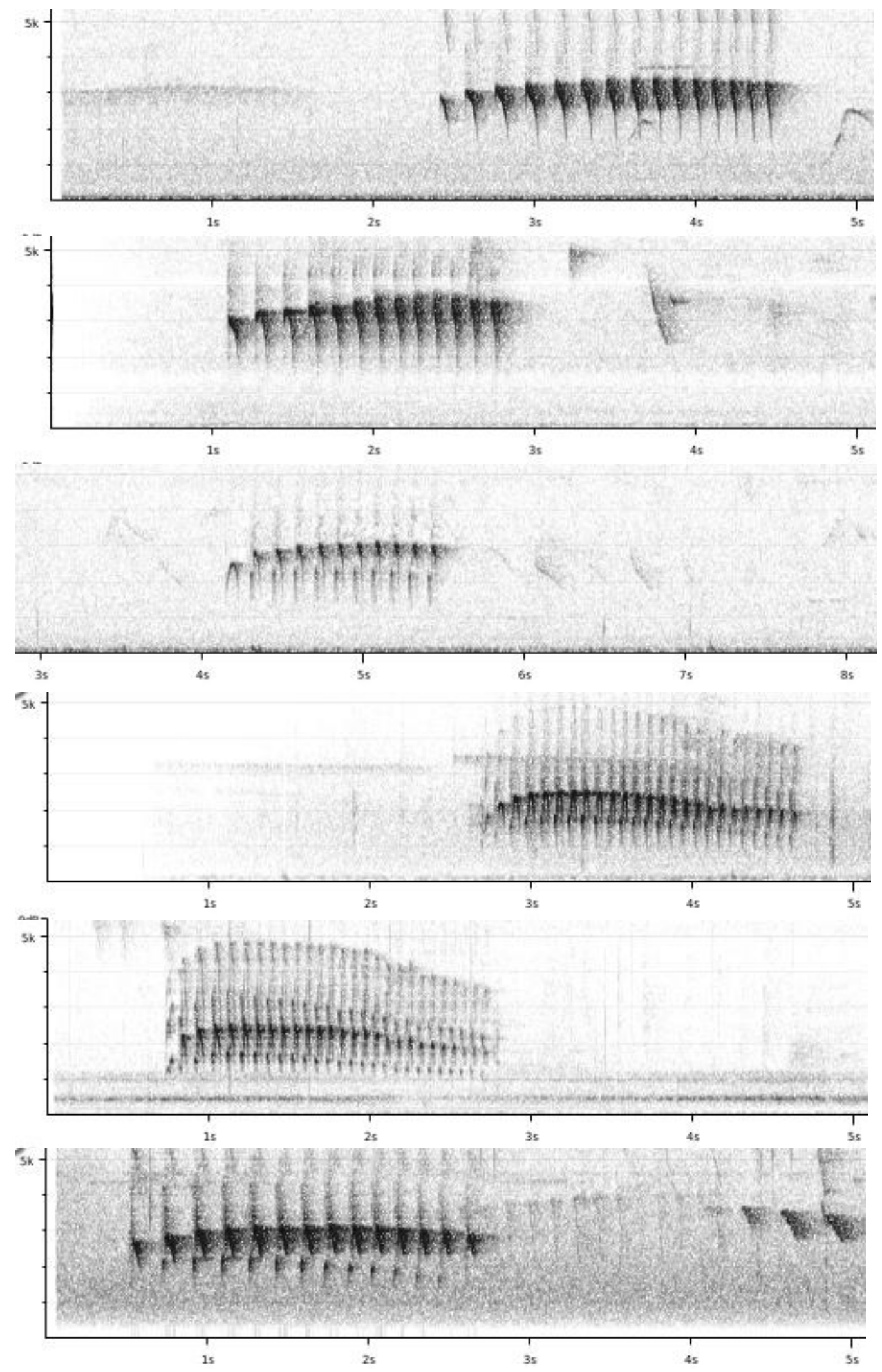

Figure 1: top to bottom: examples of loudsong from Group 1 (Mexico, Panama, Magdalena valley), Group 2 (Venezuela, Brazil) and Group 3 (Ecuador) 

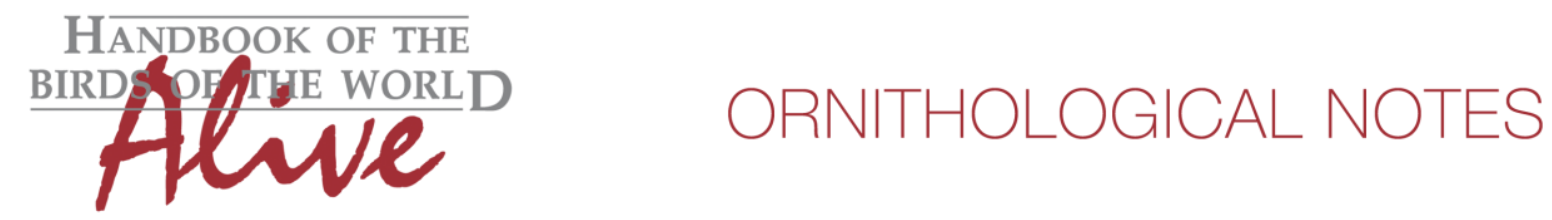

There is quite some variability in song within each group, to some extent because some recordings are made after playback, which in this particular case clearly creates changes from the natural song. Nevertheless we can discern some differences:

Birds from Central America and Magdalena valley have a rather low number of notes, delivered at a slow speed and at a high pitch. Typically, towards the end, notes hardly fall in pitch, resulting in a high end-frequency.

Song of birds West of the Andes typically have more notes ending in a trill (but not always), notes are delivered at a faster pace and are lower in pitch, with a clear decrease in pitch towards the end resulting in a low end-frequency.

Birds of W Ecuador seem to be intermediate, although closer to Central America birds.

It is clear that there are important vocal differences between the 3 identified groups, but more work is needed. It seems in particular important to compare loudsongs which were uttered under similar natural conditions. At the other hand, we should be aware of the full extent of variation within each group.

It seems however likely that vocal differences between Group 1 and Group 2 will result in a score of about 4, mainly based on differences in number of notes, maximum frequency and average pace.

This note was finalized on 18th June 2015 , using sound recordings available on-line at that moment. We would like to thank in particular the many sound recordists who placed their recordings for this species on XC.

\section{References}

Tobias, J.A., Seddon, N., Spottiswoode, C.N., Pilgrim, J.D., Fishpool, L.D.C. \& Collar, N.J. (2010). Quantitative criteria for species delimitation. Ibis 152(4): 724-746.

\section{Recommended citation}

Boesman, P. (2016). Notes on the vocalizations of Dusky Antbird (Cercomacra tyrannina). HBW Alive Ornithological Note 56. In: Handbook of the Birds of the World Alive. Lynx Edicions, Barcelona. (retrieved from http://www.hbw.com/node/931935 on 30 April 2016). 